\title{
0542 ECONOMIC EVALUATION OF DOMESTIC VIOLENCE IN FRANCE
}

M Nectoux, C Mugnier, S Baffert, B Thelot*, M Albagli Correspondence: PSYTEL, 33 rue du Commandant Mouchotte 75014 Paris, 75014, France

10.1136/ip.2010.029215.542

Objective To evaluate the cost of domestic violence in France.

Method This work was a part of a European programme (DAPHNE). The consequences of violence were listed. The data which allow quantifying these consequences were collected and expressed in monetary terms. The reference for the cost calculation was the incidence of the violence; the costs or the parameters of costs were accumulated since the beginning of the events. The cost of domestic violence was estimated from the view point of the society based on published data, institutional sources, field studies and experts opinions. The sources of data came from medical, judicial, associative spheres and from national inquiries in health.

Results The total cost of domestic violence in France was estimated at 2472 million euros per year (between 1.7 and 3.5 billion euros). This cost was detailed in: healthcare costs (483 million); use of the police and justice services (235 million); costs of the social consequences, particularly the use of the social security benefits (120 million); human costs of the rapes and prejudices (535 million); production losses due to the deaths, the imprisonments and absenteeism (1099 million, more of $40 \%$ of the total).

Conclusion Although the data were often incomplete and required hypotheses for the calculations, it may be concluded that by increasing by one euro the budget of the prevention policies of the domestic violence, one could save up to 87 euro of societal expenses, among which 30 euro of direct expenses. 